\title{
Motivational stages of adolescent smoking initiation: predictive validity and predictors of transitions
}

Citation for published version (APA):

Kremers, S. P. J., de Vries, N. K., Mudde, A. N., \& Candel, M. J. J. M. (2004). Motivational stages of adolescent smoking initiation: predictive validity and predictors of transitions. Addictive Behaviors, 29(4), 781-789. https://doi.org/10.1016/j.addbeh.2004.02.007

Document status and date:

Published: 01/01/2004

DOI:

10.1016/j.addbeh.2004.02.007

Document Version:

Publisher's PDF, also known as Version of record

Document license:

Taverne

Please check the document version of this publication:

- A submitted manuscript is the version of the article upon submission and before peer-review. There can be important differences between the submitted version and the official published version of record.

People interested in the research are advised to contact the author for the final version of the publication, or visit the DOI to the publisher's website.

- The final author version and the galley proof are versions of the publication after peer review.

- The final published version features the final layout of the paper including the volume, issue and page numbers.

Link to publication

\footnotetext{
General rights rights.

- You may freely distribute the URL identifying the publication in the public portal. please follow below link for the End User Agreement:

www.umlib.nl/taverne-license

Take down policy

If you believe that this document breaches copyright please contact us at:

repository@maastrichtuniversity.nl

providing details and we will investigate your claim.
}

Copyright and moral rights for the publications made accessible in the public portal are retained by the authors and/or other copyright owners and it is a condition of accessing publications that users recognise and abide by the legal requirements associated with these

- Users may download and print one copy of any publication from the public portal for the purpose of private study or research.

- You may not further distribute the material or use it for any profit-making activity or commercial gain

If the publication is distributed under the terms of Article $25 \mathrm{fa}$ of the Dutch Copyright Act, indicated by the "Taverne" license above, 


\title{
Motivational stages of adolescent smoking initiation: predictive validity and predictors of transitions
}

\author{
S.P.J. Kremers ${ }^{\mathrm{a}, *}$, H. de Vries ${ }^{\mathrm{a}}$, A.N. Mudde ${ }^{\mathrm{b}}$, M. Candel ${ }^{\mathrm{c}}$ \\ ${ }^{\mathrm{a}}$ Department of Health Education and Health Promotion, Faculty of Health Sciences, Universiteit Maastricht, \\ P.O. Box 616, 6200 MD Maastricht, The Netherlands \\ ${ }^{\mathrm{b}}$ School of Psychology, Open Universiteit Nederland, The Netherlands \\ ${ }^{\mathrm{c}}$ Department of Methodology and Statistics, Faculty of Health Sciences, Universiteit Maastricht, The Netherlands
}

\begin{abstract}
The present study tested the use and validity of a stage model of adolescent smoking initiation. The model aims to identify adolescents who are currently not smoking, but who are cognitively predisposed to start smoking in the future. Research on subtypes within the precontemplation stage of adolescent smoking initiation and the concept of susceptibility to smoking led to the construction of a motivational stage model of four distinct stages: committer, immotive, progressive, and contemplator. Using longitudinal data on a large international sample of European adolescents $(n=7117)$, the model proved to have value in predicting smoking initiation at 12 months follow up. The odds ratio to take up regular smoking behavior appeared to double with each forward stage transition. Although effect sizes were small to moderate, unique predictors of transitions from the various stages were identified. Implications of the findings are discussed.
\end{abstract}

(C) 2004 Elsevier Ltd. All rights reserved.

Keywords: Adolescence; Tobacco smoking; Psychodiagnostic typologies

\section{Introduction}

Traditionally, smoking onset by adolescents has been studied in terms of recent smoking behavior. Consequently, the population under study is usually categorized into two or more behavioral categories of smoking (e.g., nonsmokers, experimenters, and

* Corresponding author. Tel.: +31-43-3882431; fax: +31-43-3671032.

E-mail address: s.kremers@gvo.unimaas.nl (S.P.J. Kremers). 
regular smokers; Mayhew, Flay, \& Mott, 2000). However, nonsmoking adolescents can also be categorized into different groups, based on their cognitive characteristics (e.g., Pierce, Farkas, Evans, \& Gilpin, 1995). It may be possible to identify adolescents who are currently not smoking, but who are cognitively predisposed or motivated to start smoking in the future.

Kremers, Mudde, and De Vries (2001) integrated concepts of the Stages of Change Construct (SCC; Prochaska \& DiClemente, 1983) and susceptibility (Pierce et al., 1995) in a cross-sectional study. The results of that study indicated that the group of smoking initiation precontemplators should not be viewed as one homogenous group. Three subtypes within precontemplation were identified: progressives, immotives, and committers.

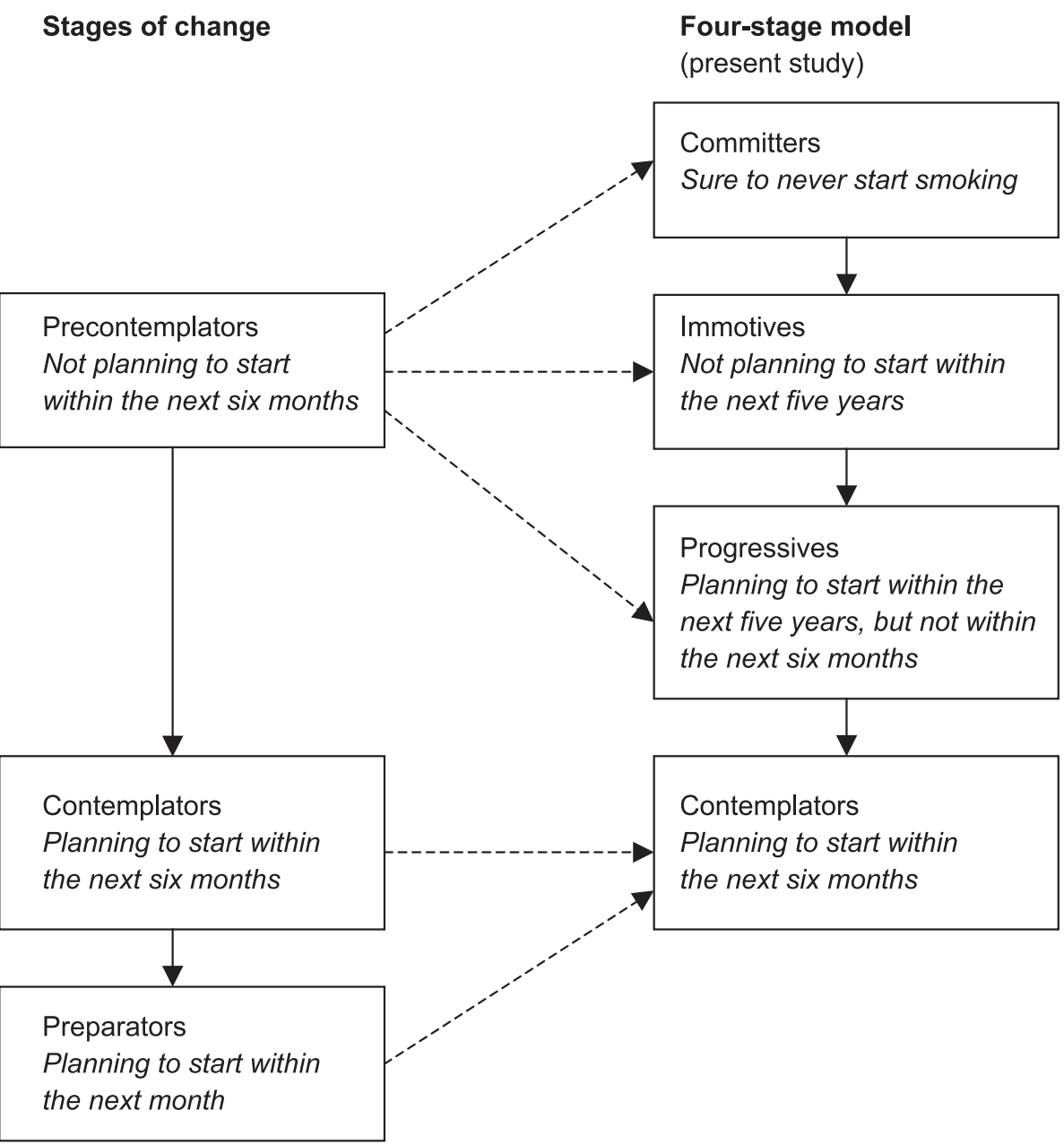

Fig. 1. Models of motivational stages of adolescent smoking initiation: the three-stage model following the SCC and the four-stage model tested in the present study. 
Progressives had concrete plans to start smoking in the future. Such concrete plans were not apparent in immotives, who only had vague plans or no plans at all to start smoking in the future. Committers not only had no plans, but they were also committed to never start smoking. They had firmly decided to remain nonsmokers. Known cognitive predictors of future smoking behavior were consistently found to differ between these subgroups. Progressives had cognitive characteristics indicating that they were most at risk of starting to smoke, while committers had characteristics indicating that they were least at risk. The study further showed that the groups of acquisition contemplators and acquisition preparators were small, and that these groups did not differ from each other with regard to cognitive characteristics. Consequently, a stage model could be constructed with four stages within the adolescent presmoking phase: committers, immotives, progressives, and contemplators (Fig. 1).

In nonexperimental settings, three types of research design can be distinguished to test stage models (Weinstein, Rothman, \& Sutton, 1998). Cross-sectional comparison of groups within different stages of change can be considered a first step in the development of a stage model. The study by Kremers et al. (2001) accomplished this first step with regard to the motivational stages of smoking initiation. A second step in the testing of a stage model incorporates the predictive validity of the stages. The first goal of the present study was to examine the predictive validity of the various stages of the four-stage model. A third step in the development of a stage model involves testing the assumption that different causal factors are important at different stages (Weinstein et al., 1998). Therefore, the second goal of the present study was to examine the predictors of progression from the stages of the four-stage model.

\section{Methods}

\subsection{Participants and recruitment}

In the present study, a large international sample of European adolescents $(n=10,170)$ was followed longitudinally. A baseline measurement was conducted in August/September 1998 and a follow-up measurement was performed 12 months later. The sample consisted of the control group of a larger, ongoing prospective study of the ESFA smoking prevention project (European Smoking prevention Framework Approach). Six member states of the European Union (Finland, Denmark, the United Kingdom, the Netherlands, Spain, and Portugal) participated in this project. Data were collected at schools using a self-administered questionnaire (see also Kremers et al., 2001).

Of the sample, 9.1\% lived in Denmark, $15.1 \%$ in Finland, $23.7 \%$ in the Netherlands, $14.3 \%$ in Portugal, $9.1 \%$ in Spain, and $28.7 \%$ in the United Kingdom. The mean age of the respondents at baseline was 13.3 years $($ S.D. $=0.7)$, and $50.5 \%$ were males. Due to missing or incomplete data on key variables, 290 cases $(3.7 \%)$ were excluded from the analysis. Information with regard to attrition rates is described in detail elsewhere (Kremers, 2002). 


\section{Measures}

\subsection{Stages of smoking initiation}

Regular smokers at baseline (those who reported smoking at least once a week; $n=389$, $5.1 \%$ ) and quitters at baseline (those who reported to have quit smoking after having smoked at least once a week; $n=141,1.8 \%$ ) were excluded from the analysis. Subsequently, respondents were classified as a result of an item that assessed the adolescents' plans to smoke in the future. Respondents were classified as contemplators $(n=77 ; 1.1 \%)$ if they planned to start within the next 6 months. Within the group who did not intend to start smoking within the next 6 months (precontemplators), three stages were distinguished: those who intended to start smoking within the next 5 years (progressives; $n=221,3.1 \%$ ), those who did not intend to start within the next 5 years but lacked a firm decision never to start smoking (immotives; $n=4336,60.9 \%$ ), and those who indicated they were sure to never start smoking and definitely not intending to smoke in the next year and definitely not intending to smoke in the future (committers; $n=2483,34.9 \%$ ).

\subsection{Cognitive determinants of smoking behavior}

Several psychosocial characteristics were measured in the present study (see Kremers et al., 2001 for more information on the exact items). Two scales of five items were constructed regarding smoking-related beliefs, one for the pros of smoking $(\alpha=.63)$ and one for the cons of smoking $(\alpha=.65)$. Three components of social influence were assessed with regard to parental influence and peer influence: perceived social norm, perceived social pressure, and perceived smoking behavior. Social norm was assessed using items with seven answering categories on perceptions of individuals on whether parents (father and mother; $\alpha=.78$ ) and peers (best friend and friends in general; $\alpha=.79$ ) think they should smoke or not. Social pressure was assessed using items with five answering categories on perceived pressure from parents (father and mother; $\alpha=.78$ ) and peers (best friend and friends; $\alpha=.71$ ). Perceived behavior was measured by asking whether mother, father, best friend, and friends smoked or not. Perceived smoking behavior was defined as an index of parental smoking behavior and of peers' smoking behavior. Self-efficacy expectations were measured by 12 items on a seven-point scale, derived from a validated instrument by Lawrance (1988). The items refer to the respondents' perception of their ability to refrain from smoking when they are with friends (four items; $\alpha=.93$ ), when they have certain emotions (four items; $\alpha=.96$ ), and when they have opportunities to smoke (four items; $\alpha=.95$ ). External variables included in the study were country, gender, age, and experimenting behavior.

\subsection{Statistical analysis}

Three sets of analyses were performed. Firstly, percentages of transitions from the various stages were assessed. Secondly, odds ratios were computed to test the predictive validity of the stages with regard to the transition towards regular smoking behavior. These odds ratios 
were corrected for the covariates gender, age, country, and experimenting behavior, using logistic regressions. Each stage was tested against every other stage, implying that three of the four stages were used as reference category once. Thirdly, predictors of transitions were studied using separate analyses of variance. With regard to all cognitive determinants, standardized $T$ scores were computed with a mean of 50 and a standard deviation of 10 . Stage transition status after 12 months was used as the independent grouping variable and the cognitive characteristics as the dependent variables. We used the magnitude of the effect size $\left(\omega^{2}\right)$ as a source of information, since it is insensitive to group sizes (Tabashnick \& Fidell, 1996). Effect size interpretations were based on the descriptive guidelines proposed by Cohen (1988). A large effect size is about $14 \%$ or more of the variance $\left(\omega^{2}=.14\right)$, a medium effect size is about $6 \%\left(\omega^{2}=.06\right)$, and a small effect size is about $1 \%$ of the variance $\left(\omega^{2}=.01\right)$. Additionally, with regard to predictors of stage transitions, interactions of the cognitive characteristics with gender, age, country, and experimenting behavior were tested. Inflated type I error because of multiple testing was controlled by applying a Bonferroni correction to the interaction analyses (Tabashnick \& Fidell, 1996).

\section{Results}

\subsection{Transitions at 12 months follow-up}

Table 1 shows the transitions from stages at the baseline measurement to those at the 12 months follow-up measurement. Less than $4 \%$ of the committers at baseline had initiated regular smoking behavior at 12 months follow-up. Of the immotives at baseline, $13.2 \%$ had started smoking. One-third of the progressives at baseline had made the move to smoking behavior in the year of follow-up. More than half of the contemplators at baseline $(53.2 \%)$ had started smoking at follow-up.

\subsection{Predictive validity of the stages}

Table 2 shows the odds ratios for each stage with regard to progression to regular smoking behavior. Age, gender, country, and experimenting behavior at baseline were entered as

Table 1

Transitions from stages at baseline (T1) to those at 12 months follow-up (T2) $(N=7117)$

\begin{tabular}{lllllc}
\hline T1 & $\mathrm{T} 2$ & & \\
\cline { 2 - 6 } & $\begin{array}{l}\text { Committers } \\
(n=2322),\end{array}$ & $\begin{array}{l}\text { Immotives } \\
(n=3768),\end{array}$ & $\begin{array}{l}\text { Progressives } \\
(n=143),\end{array}$ & $\begin{array}{l}\text { Contemplators } \\
(n=98),\end{array}$ & $\begin{array}{l}\text { Smokers } \\
(n=786), \\
1.4 \%\end{array}$ \\
\hline Committers $(n=2483), 34.9 \%$ & $1509(60.8 \%)$ & $837(33.7 \%)$ & $21(0.8 \%)$ & $19(0.8 \%)$ & $97(3.9 \%)$ \\
Immotives $(n=4336), 60.9 \%$ & $791(18.2 \%)$ & $2805(64.7 \%)$ & $100(2.3 \%)$ & $68(1.6 \%)$ & $572(13.2 \%)$ \\
Progressives $(n=221), 3.1 \%$ & $18(8.1 \%)$ & $104(47.1 \%)$ & $20(9.0 \%)$ & $3(1.4 \%)$ & $76(34.4 \%)$ \\
Contemplators $(n=77), 1.1 \%$ & $4(5.2 \%)$ & $22(28.6 \%)$ & $2(2.6 \%)$ & $8(10.4 \%)$ & $41(53.2 \%)$ \\
\hline
\end{tabular}


Table 2

Odds ratios (OR) and their $95 \%$ confidence intervals (CI) of transition towards smoking behavior

\begin{tabular}{lllll}
\hline & & Reference stage & & \\
\cline { 3 - 4 } & & Committers & Immotives & Progressives \\
\hline Immotives & OR & $\mathbf{2 . 3 2}$ & & \\
Progressives & $95 \%$ CI & $\mathbf{1 . 8 3 - 2 . 9 3}$ & & \\
& OR & 4.88 & $\mathbf{2 . 1 0}$ & \\
Contemplators & $95 \%$ CI & $3.36-7.11$ & $\mathbf{1 . 5 4 - 2 . 8 8}$ & $\mathbf{1 . 9 6}$ \\
& OR & 9.53 & 4.13 & $\mathbf{1 . 1 1}-\mathbf{3 . 4 4}$ \\
\hline
\end{tabular}

Committers, immotives, and progressives were each tested as reference stage $(N=7117)$.

Reference stage, OR set at 1.00. Odds ratios corrected for age, gender, country, and experimenting behavior. Odds ratios that compare one stage with one directly preceeding it are depicted in bold.

covariates in the computation of odds ratios. The most important odds ratios are those that compare a particular stage with the one directly preceding it. In these cases (depicted in bold in Table 2), the preceding stage was used as the reference category in the regression analysis. The odds ratio of the reference category was set at 1.00. Table 2 shows that the odds ratios that compared a stage with the one directly preceding it were always approximately 2 . Since all $95 \%$ confidence intervals were larger than 1.00, it may be concluded that all differences found were statistically significant.

\subsection{Predictors of transitions}

The adolescents who had progressed during the 12 months follow-up period were compared to those who did not (i.e., those who remained in the same stage or regressed). Table 3 shows the mean $T$ scores, along with the standard deviation of the mean and the effect-size estimates $\left(\omega^{2}\right)$ for each comparison. Tests on interactions of the cognitive characteristics with gender, age, country, and experimenting behavior with regard to predictors of stage transitions did not reveal significant interactions.

Overall, adolescents who had progressed had scores on cognitive characteristics at baseline that indicated that they were at higher risk of starting to smoke than the adolescents that did not progress. Thus, adolescents who had progressed at follow-up perceived more pros of smoking at baseline, more social norms, more pressure to smoke from peers, and they perceived more smoking behavior in their environment. Moreover, they perceived fewer cons of smoking and they had a lower self-efficacy to refrain from smoking. Exceptions to this finding were the results on the perceived social pressure from the parents of committers, opportunity self-efficacy of adolescents in the progressive stage, and perceived cons of smoking among contemplators.

With regard to predictors of progression from the committer stage, almost every difference found was statistically significant at a level of $P<.05$. However, the effect-size estimate for self-efficacy to refrain from smoking when being with friends $\left(\omega^{2}=.01\right)$ was the only predictor that may be interpreted as a concept contributing markedly to the explanation of 
Table 3

Comparison between adolescents who progressed and those who did not progress (stable or regressive) in the 12 months follow-up $(n=7117)$

\begin{tabular}{|c|c|c|c|c|c|c|c|}
\hline T1 determinants & $\begin{array}{l}\text { Committers: } \\
\text { P, } n=974 \\
\text { S, } n=1509\end{array}$ & $\omega^{2}$ & $\begin{array}{l}\text { Immotives: } \\
\mathrm{P}, n=740 \\
\mathrm{~S} / \mathrm{R}, n=3596\end{array}$ & $\omega^{2}$ & $\begin{array}{l}\text { Progressives: } \\
\mathrm{P}, n=79 ; \\
\mathrm{S} / \mathrm{R}, n=142\end{array}$ & & $\begin{array}{l}\text { Contemplators: } \quad \omega^{2} \\
\text { P, } n=41 ; \\
\text { S/R, } n=36\end{array}$ \\
\hline
\end{tabular}

Attitude towards smoking

$\begin{array}{llllllll}\text { Pttitude towards smoking } & \mathrm{P} & 48.1(10.8) & 52.6(9.0) & .01 & 59.3(9.3) & .04 & 60.7(7.4) \\ & \mathrm{S} / \mathrm{R} & 47.0(10.8) & 50.6(9.1) & & 55.0(9.2) & & 58.1(11.7) \\ \text { Cons } & \mathrm{P} & 52.8(9.1) & 46.8(10.3) & .01 & 38.8(10.6) & .02 & 38.6(8.3) \\ & \mathrm{S} / \mathrm{R} & 53.4(9.1) & 49.3(9.5) & & 42.3(11.4) & & 37.2(12.8)\end{array}$

Perceived social norm to smoke

Parents $\quad P \quad 48.0(9.0)$

$\begin{array}{lll} & \mathrm{P} & 48.0(9.0) \\ \text { Peers } & \mathrm{S} / \mathrm{R} & 47.3(8.5) \\ & \mathrm{P} & 47.0(9.3) \\ & \mathrm{S} / \mathrm{R} & 46.4(9.6)\end{array}$

$\begin{array}{lll}51.7(10.1) & & 56.6(12.4) \\ 50.9(10.2) & & 55.3(11.9) \\ 53.1(10.0) & .01 & 57.8(11.0) \\ 51.1(9.6) & & 56.0(10.7)\end{array}$

$55.5(11.8)$

$51.9(12.6)$

$58.3(7.4)$

$57.4(10.3)$

.01

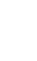


within the contemplator stage were relatively large. Emotional self-efficacy resulted in the largest effect size found in this study ( $8 \%$ of explained variance). Furthermore, the perceived pressure and smoking behavior of peers, and the efficacy to refrain from smoking when being with friends also proved to be important predictor variables.

\section{Discussion}

The present study investigated the predictive validity and predictors of transition of a motivational stage model of adolescent smoking initiation. The model combines the Stages of Change Construct (Prochaska \& DiClemente, 1983) with the concept of susceptibility to smoking (Pierce et al., 1995). The new stage model consists of four distinct stages: committers, immotives, progressives, and contemplators. The four-stage model proved to have value in predicting smoking initiation at 12 months follow-up. Furthermore, predictors of progression from the various stages were identified, some of which uniquely predicted specific transitions. Prokhorov et al. (2002) recently showed similar results with a construct that integrated Stages of Change and susceptibility to smoking.

The conciseness and theoretical background of the SCC makes it a useful tool to study adolescent smoking initiation. Viewing adolescent smoking initiation as a dynamic process rather than a static dichotomous characteristic is a valid and fruitful starting point. However, studies on the concept of susceptibility and on subtypes within the precontemplation stage have proven that the SCC cannot be simply mirrored in order to be validly applied to adolescent smoking initiation. In our view, the time framing of the distinct stages of the SCC should be critically and specifically examined for the various possible health behaviors and target groups.

The present study has shown that a useful theory on the adolescent smoking initiation process should incorporate motivational stages of change. However, in order to come to a generally accepted model of the uptake process, more research is needed on the relationship between early behavioral stages of smoking initiation (i.e., initial trying and experimenting) and the motivational stages of change. Since the groups of progressives and contemplators have been found to be relatively small, the practical use of distinguishing between these two stages should also receive attention.

\section{Acknowledgements}

This study was funded with the assistance of the European Community, Fund for Tobacco Research and Information (Regulation (EC) No 2427/93). We thank all ESFA team members for their contributions to the project.

\section{References}

Cohen, J. (1988). Statistical power analysis for the behavioral sciences. Hillsdale: Erlbaum.

Kremers, S. P. J. (2002). On your marks: Revising, testing and integrating stage models of smoking initiation. Maastricht: Unigraphic. 
Kremers, S. P. J., Mudde, A. N., \& De Vries, H. (2001). Subtypes within the precontemplation stage of adolescent smoking acquisition. Addictive Behaviors, 26, 237-251.

Lawrance, L. (1988). Validation of a self-efficacy scale to predict adolescent smoking. Health Education Research, 4, 351-360.

Mayhew, K. P., Flay, B. R., \& Mott, J. A. (2000). Stages in the development of adolescent smoking. Drug and Alcohol Dependence, 59(Suppl. 1), S61-S81.

Pierce, J. P., Farkas, A. J., Evans, N., \& Gilpin, E. A. (1995). An improved surveillance measure for adolescent smoking? Tobacco Control, 4, S47-S56.

Prochaska, J. O., \& DiClemente, C. C. (1983). Stages and processes of self-change of smoking: Toward an integrative model of change. Journal of Consulting and Clinical Psychology, 51, 295-304.

Prokhorov, A. V., De Moor, C. A., Hudmon, K. S., Hu, S., Kelder, S. H., \& Gritz, E. R. (2002). Predicting initiation of smoking in adolescents: Evidence for integrating the stages of change and susceptibility to smoking constructs. Addictive Behaviors, 27, 697-712.

Tabachnick, B. G., \& Fidell, L. S. (1996). Using multivariate statistics (3rd ed.). New York: HarperCollins Publishers.

Weinstein, N. D., Rothman, A. J., \& Sutton, S. R. (1998). Stage theories of health behavior: Conceptual and methodological issues. Health Psychology, 17, 290-299. 